\title{
Article \\ Dual-Polarized Dual-Loop Double-Slot Antipodal Tapered Slot Antenna for Ultra-Wideband Radar Applications
}

\author{
Guangyao Yang ${ }^{1,2}{ }^{\oplus}$, Shengbo Ye ${ }^{1, *}$, Feng Zhang ${ }^{1}$, Yicai Ji ${ }^{1,2}$, Xiaojuan Zhang ${ }^{1}$ and Guangyou Fang ${ }^{1,2}$ \\ 1 Aerospace Information Research Institute, Chinese Academy of Sciences, Beijing 100190, China; \\ yangguangyao16@mails.ucas.ac.cn (G.Y.); zhangfeng002723@aircas.ac.cn (F.Z.); ycji@mail.ie.ac.cn (Y.J.); \\ xjzhang@aircas.ac.cn (X.Z.); gyfang@aircas.ac.cn (G.F.) \\ 2 School of Electronic, Electrical and Communication Engineering, University of Chinese Academy of Sciences, \\ Beijing 100049, China \\ * Correspondence: yesb@aircas.ac.cn
}

check for updates

Citation: Yang, G.; Ye, S.; Zhang, F.; Ji, Y.; Zhang, X.; Fang, G.

Dual-Polarized Dual-Loop

Double-Slot Antipodal Tapered Slot Antenna for Ultra-Wideband Radar Applications. Electronics 2021, 10, 1377. https://doi.org/10.3390/ electronics10121377

Academic Editor: Giovanni

Andrea Casula

Received: 10 May 2021

Accepted: 6 June 2021

Published: 8 June 2021

Publisher's Note: MDPI stays neutral with regard to jurisdictional claims in published maps and institutional affiliations.

Copyright: (c) 2021 by the authors. Licensee MDPI, Basel, Switzerland. This article is an open access article distributed under the terms and conditions of the Creative Commons Attribution (CC BY) license (https:// creativecommons.org/licenses/by/ $4.0 /)$.

\begin{abstract}
The miniaturized high-gain antenna is required in portable, ultra-wideband radar systems. However, the miniaturization, ultra-wideband and high gain often restrict each other in the antenna design. In this paper, a dual-polarized, double-slot, antipodal tapered slot antenna with a doublelayer, dual-loop structure and novel slot edges is presented. The proposed magnetic dual-loop structure has the capacity to reduce the low cut-off frequency of the double-slot tapered slot antenna by weakening the resonance and coupling. In addition, the high gain, low sidelobe level (SLL), and low cross-polarization level are achieved in the boresight direction. A novel gradient slot profile is designed to improve the low-frequency directivity of the tapered slot antenna without affecting the matching. To feed the antenna elements, a kind of wideband, balun-divider structure is designed. The dual-polarized antenna is combined by two orthogonal elements in a cross configuration without galvanic contact or influence to performance. The measured results show that the impedance bandwidth of the proposed antenna is $0.6 \sim 4 \mathrm{GHz}$, and the maximum gain is $11 \mathrm{dBi}$. The isolation between the two antenna ports is better than $32 \mathrm{~dB}$, and the cross-polarization discrimination (XPD) is better than $20 \mathrm{~dB}$.
\end{abstract}

Keywords: ultra-wideband (UWB); dual-polarized; miniaturized; tapered slot antenna; double-slot; high gain

\section{Introduction}

Recently, dual-polarized antennas have been increasingly in demand and deeply studied in ultra-wideband (UWB) systems, such as radar, wireless communication, and microwave imaging systems [1]. Through-the-wall radar (TWR) is a kind of radar that can extract the polarization features of the human body echo and recognize its postures by using dual-polarized antennas [2]. To realize a wideband, directive, dual-polarized antenna, two elements with linear polarization are traditionally orientated into a cross shape [3]. However, miniaturization and radiation enhancement are still challenging in practical applications [4]. As a kind of travelling-wave antennas, the tapered slot antenna (TSA) is widely used to form dual-polarized TSAs owing to its advantages of low cost and low weight [5]. However, it has disadvantages of lowest frequency limitation and radiation pattern distortion at high frequencies. In particular, the conventional antipodal TSAs (ATSAs) suffer from the skew of E-field that result in poor cross polarization and beam tilt [6]. Though the UWB feeding transition of ATSA brings a wider bandwidth, it enlarges the total profile [7]. To improve the directivity, a double-slot structure was proposed by Wang et al. [8]. Many efforts have been made to develop the structure since then [9-13]. However, the existing research only focuses on high-frequency performance, ignoring the large size of this structure. For TSAs that are uniplanar or antipodal, single-slot 
or double-slot, orthogonal design without galvanic contact and polarization interference remains an important research field [14-20].

In this paper, a modified dual-polarized double-slot ATSA is designed. The dual-loop structure, as well as Fibonacci slot edges (FSEs), are applied to form a symmetric structure to improve the antenna performance. A compact balun-divider structure is proposed to minimize the total length. Simulated and measured results both show that the lowest frequency is greatly reduced, and the high gain is maintained. By a smart design of the double-layer structure, the elements are easy to be integrated. The elements of the integrated dual-polarized antenna keep good performance. The loss materials, such as brick, concrete, and wood, can be penetrated by the low-frequency electromagnetic waves with less energy loss. Thus, the proposed miniaturized antenna is suitable for portable TWR systems. This paper is organized as follows: In Section 2, the geometric structure, radiation mechanism, and feeding structure of the antenna are presented. The simulation and measured results of the antenna properties are shown in Section 3. In Section 4, the superior performance of the proposed antenna is verified by a comparison. Finally, Section 5 draws the conclusion.

\section{Antenna Geometry and Design}

The configuration of the proposed dual-polarized double-slot ATSA (DP-DSATSA) is shown in Figure 1a. The DP-DSATSA is composed of two double-slot antenna elements, which are placed in a cross shape. It is clear that the two-sided metal with rotational symmetry about the Y-axis avoids the electrical contact of the two elements. The copper on the top layer is indicated in red while the copper on the bottom layer is blue. Port 1 and Port 2 are located on the opposite side of the radiating structure, feeding the doubleslot structures of Element 1 and Element 2 by double-sided parallel strip lines (DSPSL). The details of the two double-slot antenna elements are shown in Figure 1b,c. The two elements have different feed lines and board cutting.

\subsection{Radiating Structure}

The configuration of a conventional ATSA, shown in Figure 2a, is used as a starting point for the design, and the evolutionary steps are illustrated in Figure $2 \mathrm{~b}-\mathrm{e}$. The surface current at $1 \mathrm{GHz}$ is also shown in each structure, which reveals the specific operating mechanism. The current distributions in all five figures are of the same phase and normalized to the maximum value, respectively. The substrate used for all designs is made of Rogers $4350 \mathrm{~B}$ with a relative permittivity of 3.48 and a loss tangent of 0.004 . The thickness of the substrate is chosen as $0.762 \mathrm{~mm}$. The conventional ATSA in Figure 2a, which is fed by DSPSL, has a multiple-octave bandwidth but it is limited by the main beam squint, beam split, and low directivity. Moreover, to improve the matching at a low frequency, the outer edges need to be cut into rounded corners, but the gain will be further reduced. TSAs with a double-slot structure have been proposed recently to generate near-field quasi-plane waves. According to the state-of-the-art design theory, the two in-phase wavefronts merge into one at the aperture [12]. The direction of the electric field is parallel to the substrate, perpendicular to the direction of propagation. Hence, the structure shown in Figure $2 b$ is similar to an array formed by two electric dipoles. However, the asymmetric radiating arms of the double-slot antipodal tapered slot antenna (DSATSA) result in a strong coupling current between the two short arms and deterioration of low-frequency characteristics. These shortcomings are inherent and cannot be solved by optimization. Apart from the poor return loss in Figure 3a, the impact is also obvious as the two local minima on the gain curve and the two local maxima on the XPD curve, shown by the red short-dashed line in Figure 3b. As they are used to form a dual-polarized antenna, the antenna elements show further poorer performance because of the coupling current. 


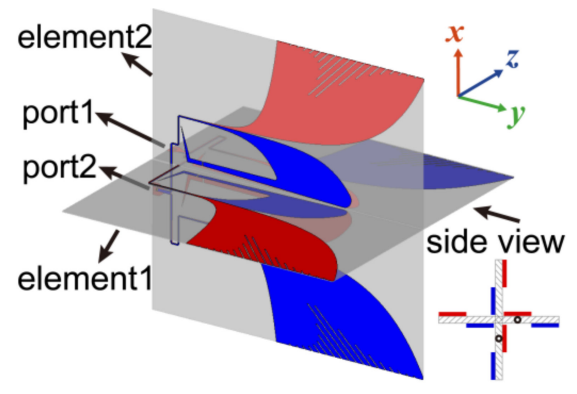

(a)

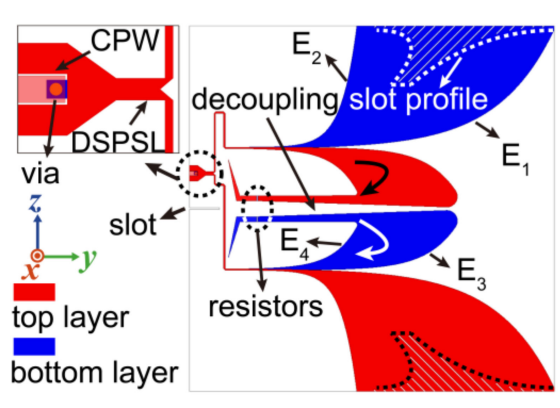

(b)

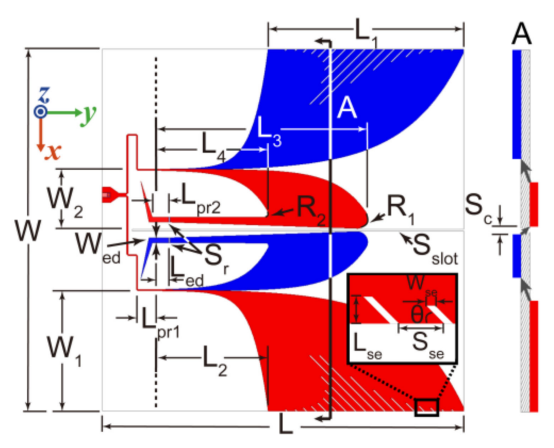

(c)

Figure 1. The structure of the proposed DP-DSATSA. (a) The total cross-shaped structure; (b) the main parts of Element 1; (c) the dimension diagram of Element 2.

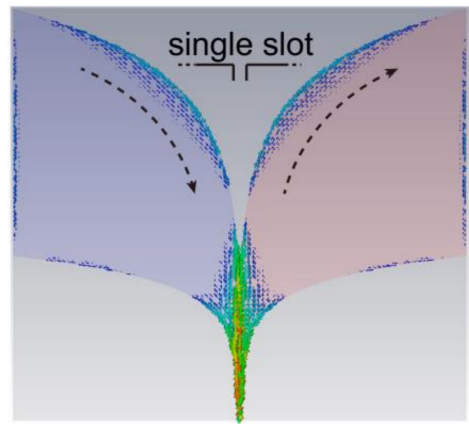

(a)

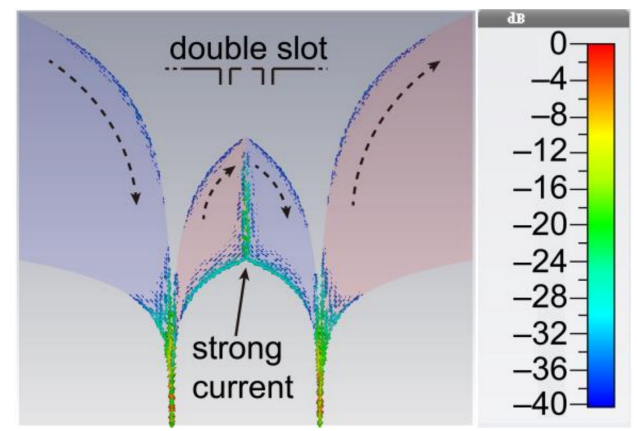

(b)

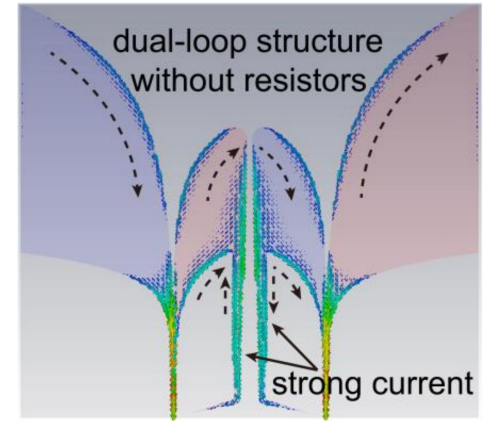

(c)

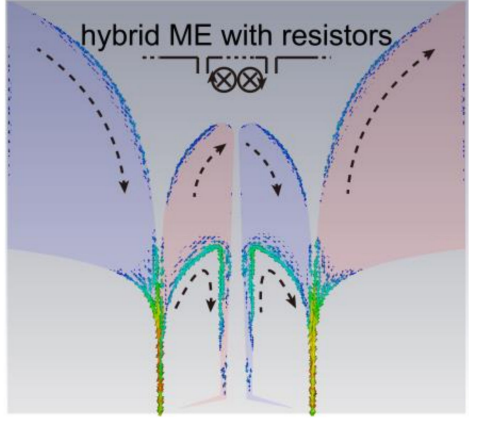

(d)

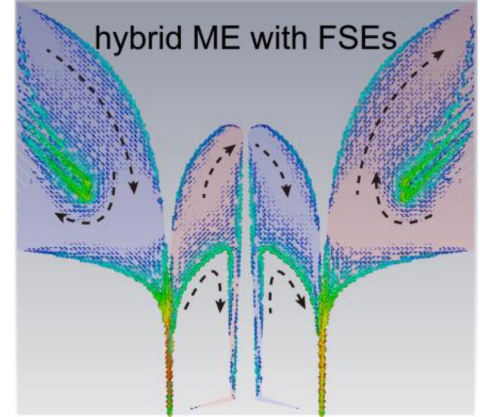

(e)

Figure 2. The surface current of ATSAs at $1 \mathrm{GHz}$ and design evolution of radiating structure with the red part as the top metal layer, the blue part as the bottom metal layer, and the light gray part as the substrate. (a) The conventional ATSA; (b) the conventional DSATSA; (c) the dual-loop DSATSA without resistors; (d) the dual-loop DSATSA; (e) the dual-loop DSATSA with FSEs. 


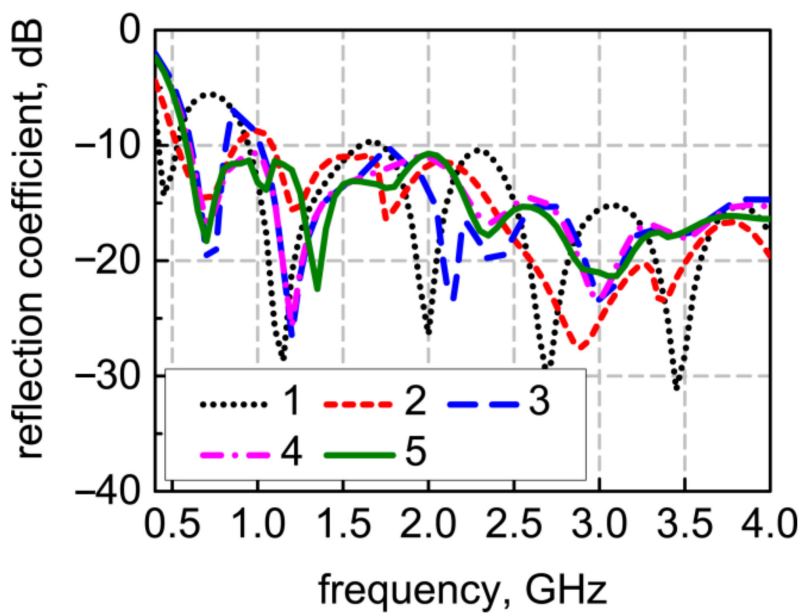

(a)

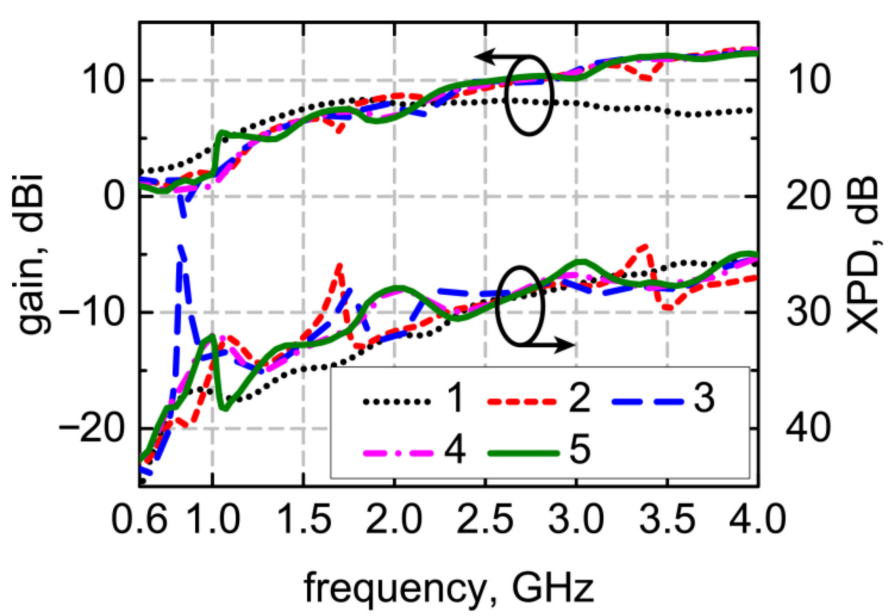

(b)

Figure 3. Performance comparison of different types of antennas (1: Conventional ATSA; 2: Conventional DSATSA; 3 : Dual-loop DSATSA without resistors; 4: Dual-loop DSATSA; 5: Dual-loop DSATSA with FSEs). (a) The reflection coefficient $\left(S_{11}\right)$; (b) the co-polarized gain and XPD at boresight.

In this paper, we focus on the optimization of the resonance structure and weakening of the coupling current. After simply applying an extended loop structure to the short arm as shown in Figure $2 c$, the current on the inner edge of the short arm $\left(E_{4}\right.$ in Figure $\left.1 b\right)$ cannot form a travelling wave. However, the coupling current is still strong. The two resonance points in Figure $3 \mathrm{~b}$ move down to the lower frequencies as shown by the blue dashed line.

By adding the resistors to the end of short arms, the current distribution on the inner and outer edges is changed. Figure 4 shows how the resistance value affects the resonance level of the Dual-loop DSATSA. When the resistance value is small, the effect of loading is not obvious, and the resonance is not improved. As the resistance increases, the loop current at inner edges is formed. Thus, the reflections occurring at inner edges are significantly reduced. Considering both the reflection coefficient and radiation characteristics, the resistance value is chosen as $220 \Omega$. Then the novel radiating part presented in Figure $2 \mathrm{~d}$ becomes a hybrid magnetoelectric structure. The two slots act as two electric dipoles, while the short arms are modified into two in-phase magnetic rings. The corresponding results are shown in Figure 3a,b with pink dash-dot lines. By removing the two sudden changes in the frequency domain, the cross-polarization of DSATSA is improved and the forward gain steadily increases without reducing efficiency. The geometry was optimized using Ansys HFSS, and the equations for edges $E_{1}-E_{4}$, referring to Figure $1 \mathrm{~b}$, and the related ranges of $x$ are defined as follows:

$$
\begin{gathered}
E_{1}: y(x)=0.08 \cdot \log _{10}\left(\frac{2 \cdot x}{0.15}+1\right)\left(0 \leq x \leq \frac{W_{1}+W_{f d} / 2}{2}-1\right) \\
E_{2}: y(x)=0.02 \cdot \log _{10}\left(\frac{2 \cdot x}{0.02}+1\right)\left(0 \leq x \leq \frac{W_{1}-W_{f d} / 2}{2}\right) \\
E_{3}: y(x)=0.04 \cdot \log _{10}\left(\frac{2 \cdot x}{0.01}+1\right)\left(0 \leq x \leq \frac{W_{2}+W_{f d} / 2}{2}-\frac{5 R_{1}}{3}\right) \\
E_{4}: y(x)=0.03 \cdot \log _{10}\left(\frac{2 \cdot x}{0.1}+1\right)\left(0 \leq x \leq \frac{W_{2}-W_{f d} / 2}{2}-\frac{3 R_{2}}{2}\right)
\end{gathered}
$$




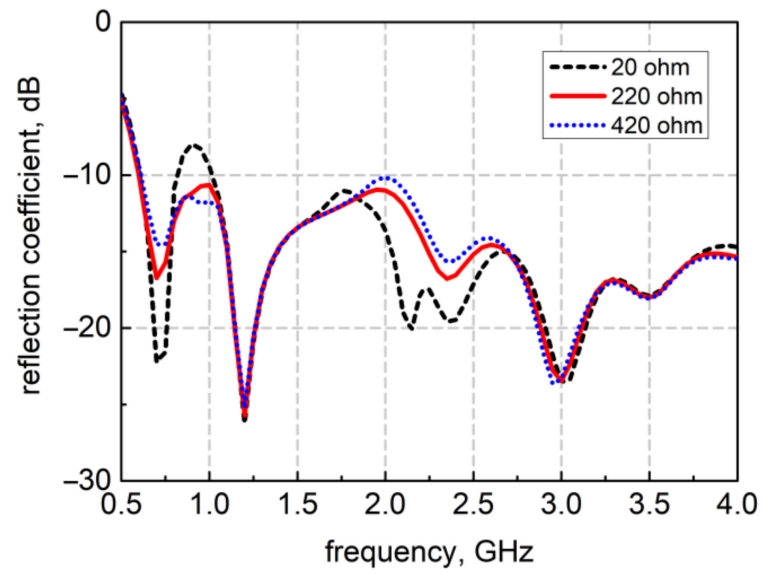

(a)

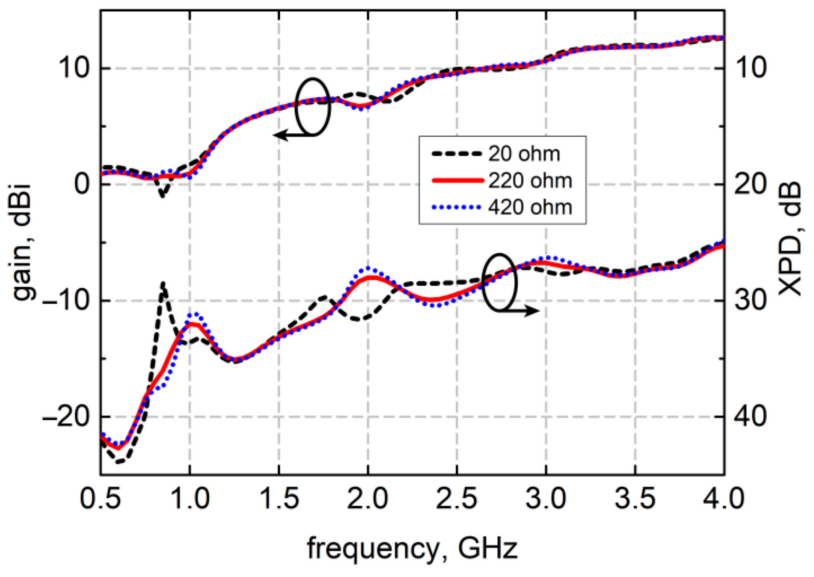

(b)

Figure 4. Performance comparison of Dual-loop DSATSA at different resistance values. (a) The reflection coefficient $\left(S_{11}\right)$; (b) the co-polarized gain and XPD at boresight.

The variables $x$ and $y$ correspond to the coordinate axis in Figure 1c. As shown in Figure 1c, the variable $W_{1}$ represents the width of the long arm, while the variable $W_{2}$ means the width of the short arm. $R_{1}$ and $R_{2}$ represent the two arc radii on the short arm. Meanwhile, the variable $W_{f d}$ is shown is Figure 5, meaning the line width of the DSPSL.

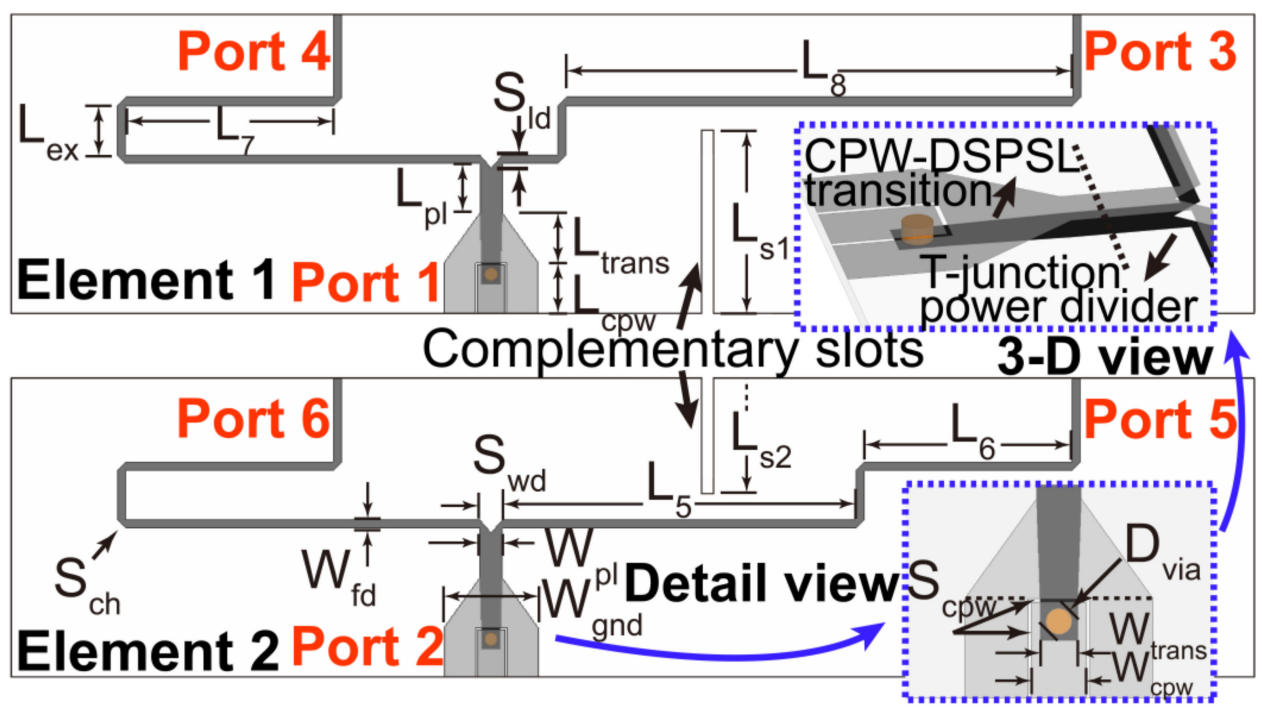

Figure 5. The configuration and dimension diagram of the balun-divider structures.

In order to enhance the radiation of the dual-loop DSATSA at low frequency, a novel Fibonacci slot profile is proposed in this paper. As shown in Figure 3b, the deterioration of the co-polarized gain is accompanied by the increase in cross polarization. By adding slots to the long arms, which are shown in Figure 2e, more surface current is excited at or above $1 \mathrm{GHz}$. The longest slots work like additional active structures and enhance the radiation of the tapered slot, resulting in improvement of the directivity. The minimal reflection is achieved by the $45^{\circ}$ inclined slots with a gradient length variation. The key active slot is related to the electrical length, so the shorter slots are activated at high frequency. The FSEs are made up of a series of grooves whose lengths $L_{s e}$ are successively increased according to Fibonacci numbers $(1,1,2,3,5,8,13,21,34)$. The numbers are generated by a recursive formula:

$$
X_{n}=X_{n-1}+X_{n-2}\left(X_{0}=X_{1}=1,2 \leq n \leq 8\right)
$$




$$
X_{n}=X_{17-n}(9 \leq n \leq 17)
$$

After the peak value, the groove length is reduced according to the mirror image of the above series. The horizontal length of the slot edge $L_{s e}$ can be calculated by the following:

$$
L_{s e}(n)=X_{n} \cdot 1 \mathrm{~mm}
$$

The inclined slots will show different profiles when the groove length increases and decreases. From the results of green solid lines in Figure 3, this design does not affect the characteristics at other frequencies. The gain and XPD at around $1 \mathrm{GHz}$ are greatly improved.

\subsection{Feeding Structure}

The balun-divider structure is designed to output two signals with equal amplitude and phase to excite the double-slot radiating structure. A shortened CPW-DSPSL transition is proposed to realize the transformation from unbalanced mode to balanced mode. The characteristic impedance of $50 \Omega$ is unchanged in this transition. The central strip of $\mathrm{CPW}$ is converted to the bottom layer, and the ground planes on both sides are combined together on the top layer. The T-junction power divider placed behind the balun is modeled based on DSPSL, as shown in Figure 5. The output impedance $Z_{02}$ and $Z_{03}$ of this low-loss divider can be jointly determined by the input impedance $Z_{01}$ and the formula as follows:

$$
Z_{01}=\left(\frac{1}{Z_{02}}+\frac{1}{Z_{03}}\right)^{-1}=\frac{Z_{02} \cdot Z_{03}}{Z_{02}+Z_{03}}
$$

The calculated output impedance, which is also the impedance of DSPSL and the input impedance of double-slot ATSA, is $100 \Omega$. To complete the structure of the dual-polarized antenna, the novel radiating structure proposed in this paper is symmetrical, and a couple of complementary slots can be cut in the center of the substrate. Meanwhile, the feeding structures need to be offset from the center to avoid affecting the slotting. The layout of the DSPSL is specifically designed to ensure equal input signals, as shown in Figure 5.

Figure 6a shows that the $S_{11}$ of the input port is less than $-20.5 \mathrm{~dB}$ from 0.5 to $4 \mathrm{GHz}$, while the insertion losses from the input ports to output ports are both less than $0.8 \mathrm{~dB}$. The proposed feeding structure has excellent S-parameters among the ultra-wideband, ensuring a minimal insertion loss. To form a symmetric beam at the boresight direction, the amplitude imbalance and phase imbalance between the output ports are vital indexes in the design of the divider, affecting the boresight beam symmetry. The simulated results are presented in Figure $6 \mathrm{~b}$. The differences in amplitude and phase fluctuate around zero in the frequency domain, which are $0.3 \mathrm{~dB}$ and $1.5 \mathrm{deg}$, respectively. The dimensions of the radiation part and feeding structures are shown in Table 1. By integrating the radiation structure and balun-divider structure, two complete dual-loop loaded DSATSA elements can be obtained, as shown in Figure 1b,c. The dual-polarized antenna can be formed by integrating the two elements together. 


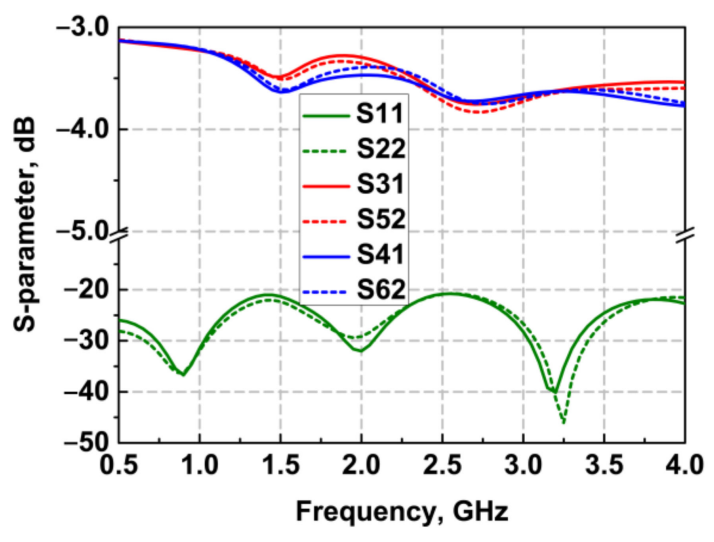

(a)

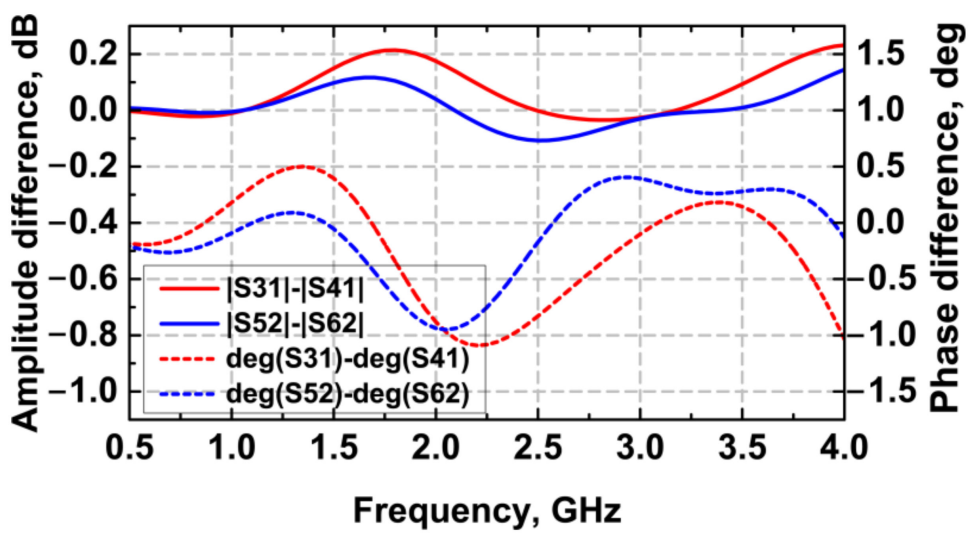

(b)

Figure 6. The performance of the balun-divider structure. (a) The reflection coefficients of the input ports and insertion losses from input ports to output ports; (b) the amplitude imbalance and phase imbalance between the output ports.

Table 1. The parameters of the proposed antenna.

\begin{tabular}{cccccc}
\hline Params. & Value $\mathbf{( m m )}$ & Params. & Value $(\mathbf{m m})$ & Params. & Value $(\mathbf{m m})$ \\
\hline $\mathrm{L}$ & 220 & $\mathrm{~L}_{\mathrm{s} 2}$ & 202.5 & $\mathrm{~W}_{\text {gnd }}$ & 9.45 \\
$\mathrm{~L}_{1}$ & 120 & $\mathrm{~L}_{\mathrm{pr} 1}$ & 10 & $\mathrm{~W}_{\text {trans }}$ & 1.9 \\
$\mathrm{~L}_{2}$ & 70 & $\mathrm{~L}_{\mathrm{pr} 2}$ & 10 & $\mathrm{D}_{\text {via }}$ & 1.3 \\
$\mathrm{~L}_{3}$ & 130 & $\mathrm{~L}_{\mathrm{cpw}}$ & 5 & $\mathrm{R}_{1}$ & 6 \\
$\mathrm{~L}_{4}$ & 70 & $\mathrm{~L}_{\text {trans }}$ & 5 & $\mathrm{R}_{2}$ & 2 \\
$\mathrm{~L}_{5}$ & 37.54 & $\mathrm{~W}$ & 220 & $\mathrm{~S}_{\mathrm{c}}$ & $2-9.6$ \\
$\mathrm{~L}_{6}$ & 21.72 & $\mathrm{~W}_{1}$ & 74.07 & $\mathrm{~S}_{\mathrm{r}}$ & 1 \\
$\mathrm{~L}_{7}$ & 21.72 & $\mathrm{~W}_{2}$ & 35.43 & $\mathrm{~S}_{\mathrm{ch}}$ & 0.82 \\
$\mathrm{~L}_{8}$ & 51.72 & $\mathrm{~W}_{\mathrm{ed}}$ & 3 & $\mathrm{~S}_{\text {ld }}$ & 1.32 \\
$\mathrm{~L}_{\mathrm{ex}}$ & 5 & $\mathrm{~W}_{\mathrm{fd}}$ & 0.82 & $\mathrm{~S}_{\mathrm{se}}$ & 5 \\
$\mathrm{~L}_{\mathrm{ed}}$ & 9 & $\mathrm{~W}_{\mathrm{pl}}$ & 2.25 & $\mathrm{~S}_{\mathrm{wd}}$ & 2.25 \\
$\mathrm{~L}_{\mathrm{pl}}$ & 5 & $\mathrm{~W}_{\mathrm{se}}$ & 1 & $\mathrm{~S}_{\mathrm{cpw}}$ & 0.12 \\
$\mathrm{~L}_{\mathrm{s} 1}$ & 17.5 & $\mathrm{~W}_{\mathrm{cpw}}$ & 2.75 & $\mathrm{~S}_{\mathrm{slot}}$ & 1 \\
\hline
\end{tabular}

\section{Results}

On the left part of Figure 7, a fabricated prototype of the DP-DSATSA is presented. The welding details of resistor and coaxial joint are displayed. From the back view at the center of Figure 7, the two feeding ports and crossed feeding circuits are shown clearly. The reflection coefficients of the two feeding ports are measured, using a vector network analyzer named Keysight E5063A. The far-field characteristics are measured in a microwave anechoic chamber, which is shown on the right part of Figure 7.

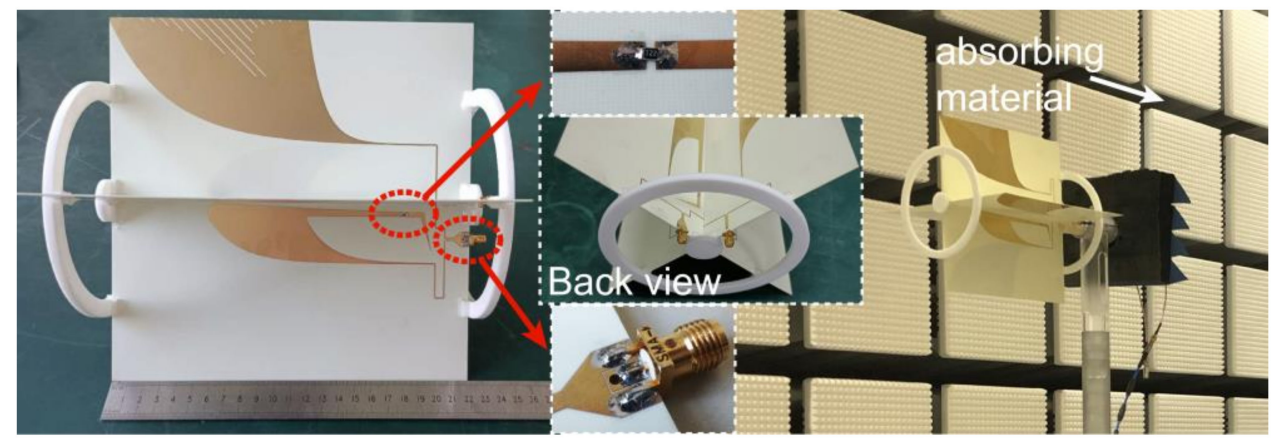

Figure 7. The fabricated dual-loop loaded DP-DSATSA and the test scene in the microwave anechoic chamber. 
The DSATSA elements measured as parts of dual-polarized antenna both have impedance bandwidths from $0.6 \mathrm{GHz}$ to $4 \mathrm{GHz}$ with $S_{11}$ less than $-10 \mathrm{~dB}$, as displayed in Figure 8a. The simulated and the measured mutual coupling results $\left(S_{21}\right)$ between the two ports are lower than -30 and $-32 \mathrm{~dB}$, respectively. The simulated efficiency of the antenna with Port 1 or Port 2 excited separately is shown in Figure $8 \mathrm{~b}$. The efficiency of each element is higher than $80 \%$ through the whole band.

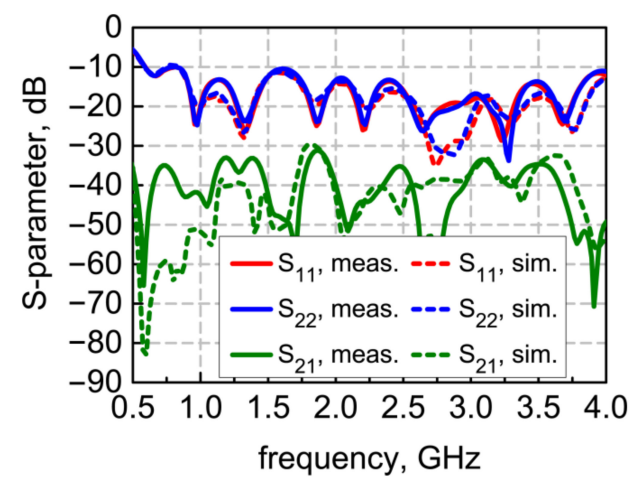

(a)

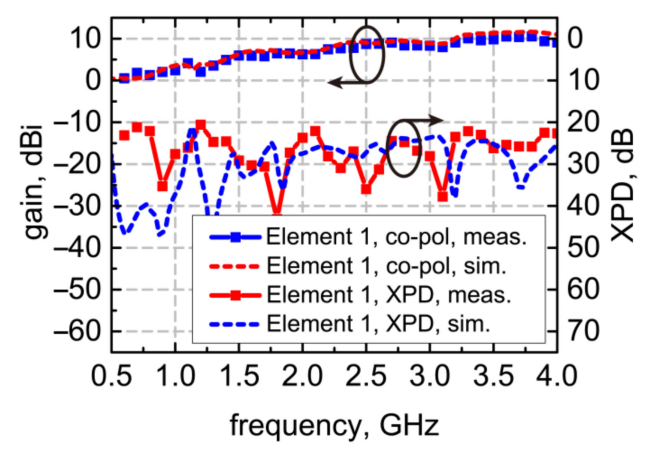

(c)

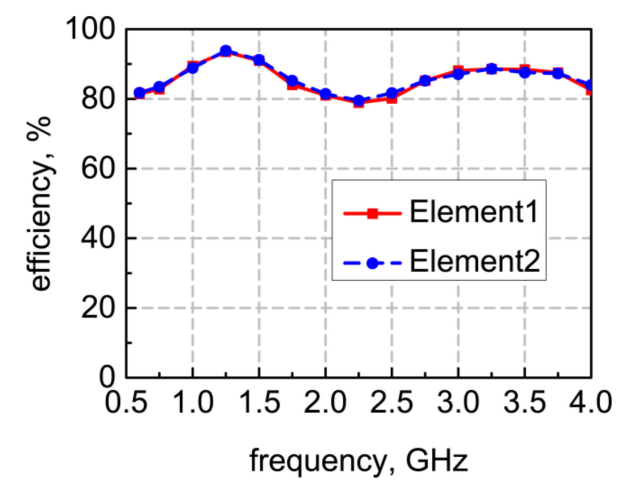

(b)

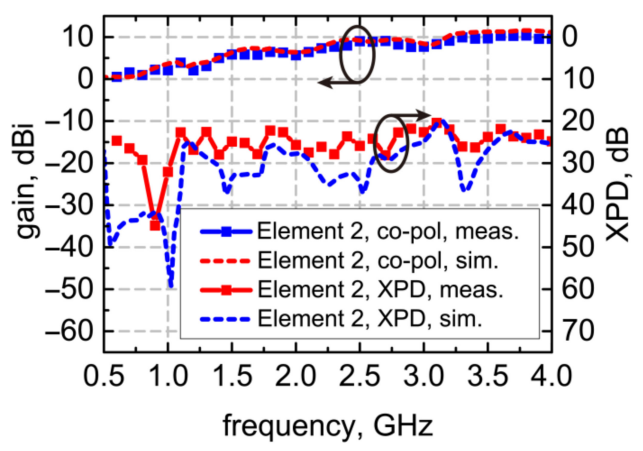

(d)

Figure 8. The simulated and measured results of the proposed DP-DSATSA. (a) Measured and simulated S-parameters; (b) efficiency of elements in the DP-DSATSA; (c) measured and simulated gain of Element 1 in the DP-DSATSA; (d) measured and simulated gain of Element 2 in the DPDSATSA.

In Figure $8 \mathrm{c}, \mathrm{d}$, the simulated and the measured far-field characteristics for both elements are shown at different frequencies up to $4 \mathrm{GHz}$. The measured gain at boresight is between 1 and $11 \mathrm{dBi}$, which is almost the same as the simulated results. The measured $X P D$ results in the direction of the boresight coincide well with the simulated ones. In the operating band, the XPD is higher than $20 \mathrm{~dB}$. The small differences between the numerical results and measured results are mainly caused by manufacturing inaccuracies, including inaccuracies in the printed circuit board manufacturing and welding.

Figure 9 displays the simulated and measured radiation patterns of the proposed elements at $0.6,1,2$, and $4 \mathrm{GHz}$. The results include 2D and 3D patterns. The 2D patterns show the detailed comparison between the simulated and measured results. In the rightmost column of Figure 9, simulated 3D patterns of Element 1 are shown since the two elements have similar radiating characteristics. It can be observed that the radiation patterns of the proposed DSATSA at frequencies below $1 \mathrm{GHz}$ are similar to the results of an omnidirectional antenna, though the E-plane beamwidth is a little narrower than the $\mathrm{H}$-plane. The reason for this phenomenon is that the double slots radiate like two finite dipoles. However, due to the FSEs, the radiating performance of the novel DSATSA at around $1 \mathrm{GHz}$ is improved. Meanwhile, it still shows remarkable radiation characteristics of low SLL, narrow beamwidth in E-plane, and symmetric patterns at high frequencies above $1 \mathrm{GHz}$. 


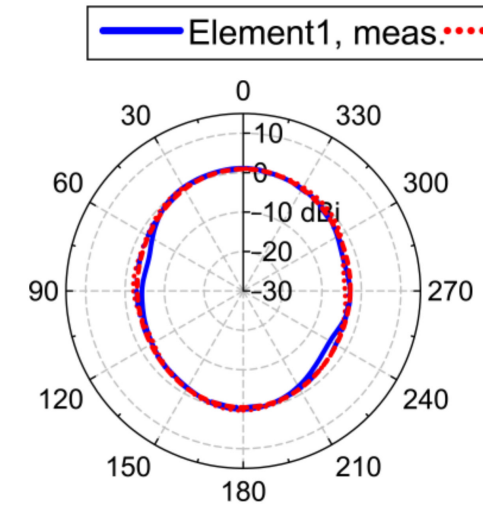

(a)

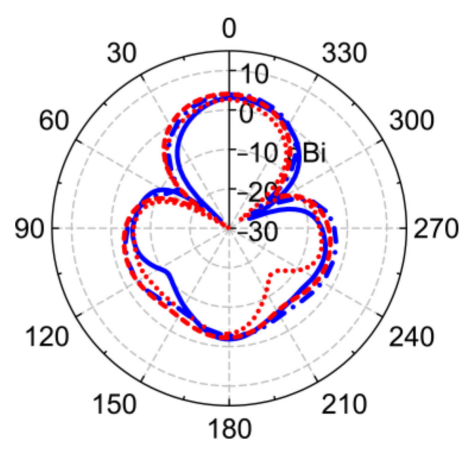

(d)

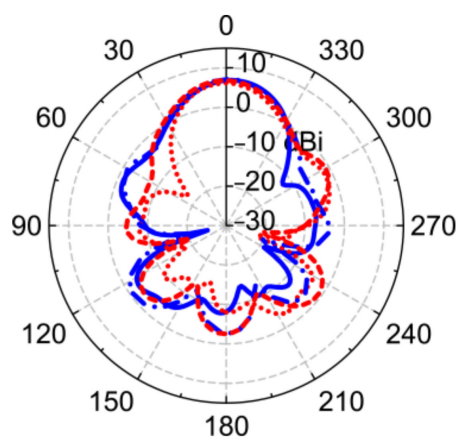

(g)

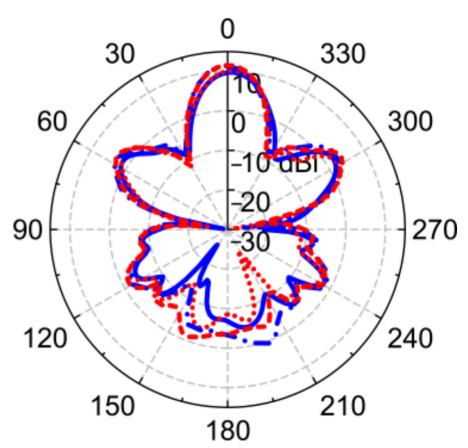

(j)

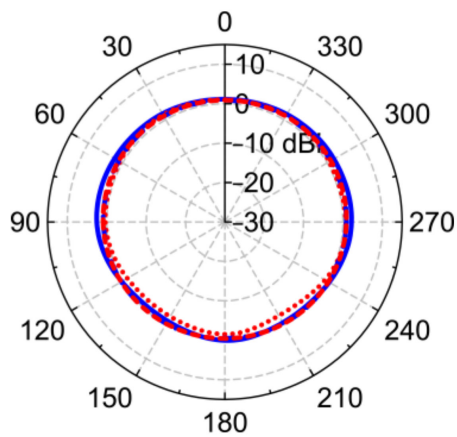

(b)

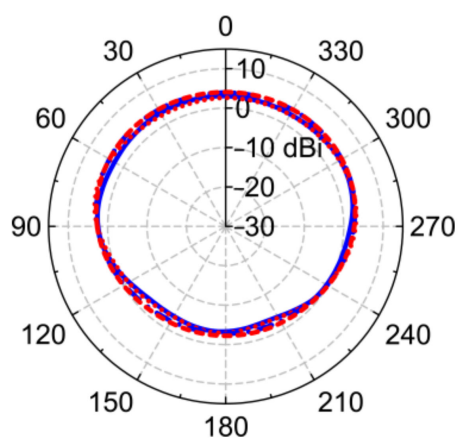

(e)

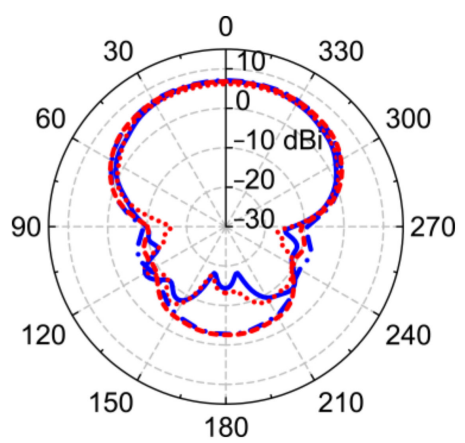

(h)

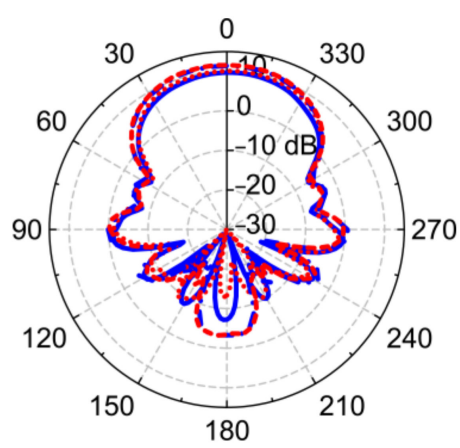

(k)

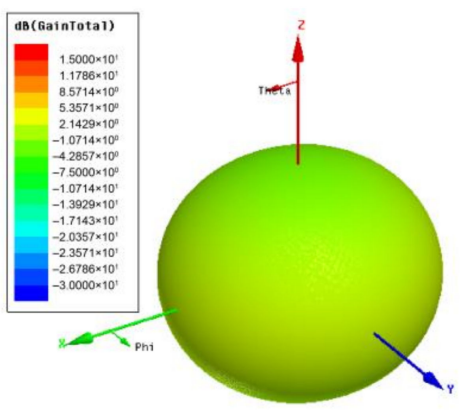

(c)

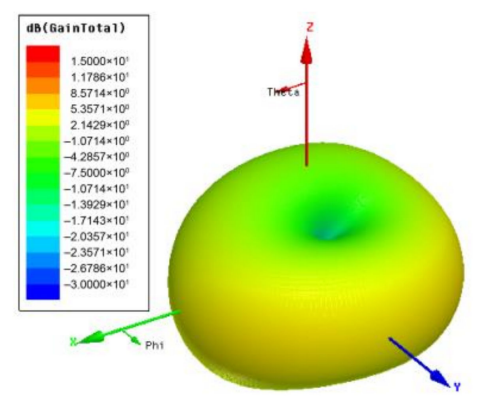

(f)

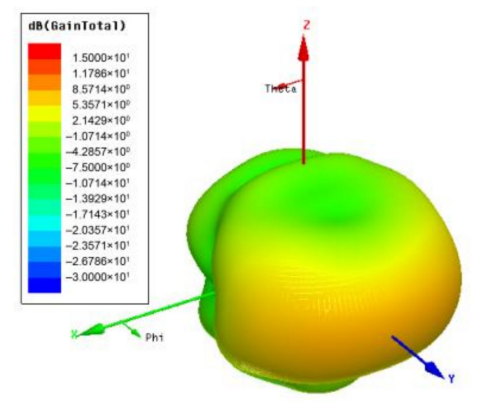

(i)

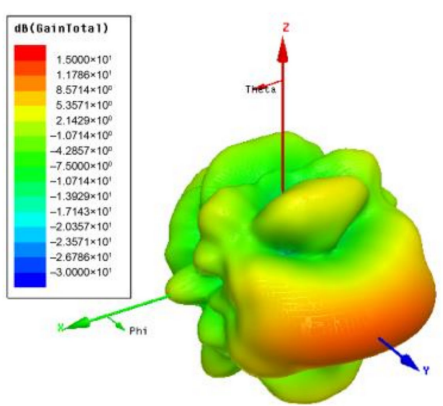

(I)

Figure 9. The simulated and measured gain patterns of the proposed elements in the DP-DSATSA. (a) E-plane patterns at $0.6 \mathrm{GHz}$; (b) H-plane patterns at $0.6 \mathrm{GHz}$; (c) 3D pattern at $0.6 \mathrm{GHz}$; (d) E-plane patterns at $1 \mathrm{GHz}$; (e) H-plane patterns at $1 \mathrm{GHz}$;(f) 3D pattern at $1 \mathrm{GHz}$; (g) E-plane patterns at $2 \mathrm{GHz}$; (h) H-plane patterns at $2 \mathrm{GHz}$; (i) 3D pattern at $2 \mathrm{GHz}$; (j) E-plane patterns at $4 \mathrm{GHz}$; (k) H-plane patterns at $4 \mathrm{GHz}$; (l) 3D pattern at $4 \mathrm{GHz}$. 


\section{Discussion}

A comparison of the characteristics with dual-polarized antenna designs using ATSAs reported in the literature is given in Table 2 . The low cut-off frequency achieved by the design proposed in this paper appears to be lower than that in reference [14-19]. The length of the radiating structure is only $190 \mathrm{~mm}$. After adding the feeding structure, the total length and width of the proposed antenna element are $220 \mathrm{~mm}$, corresponding to 0.44 times the longest operating wavelength of $50 \mathrm{~cm}$. Meanwhile, the highest port isolation and XPD are realized by the novel design accompanied by a relatively high gain. It is worth mentioning that the antenna elements of dual-polarized TSAs in the literature usually have different characteristics, especially for another DP-DSATSA, such as [18]. In the proposed design, the performance of the two elements is nearly the same. For the lens-loaded tapered slot antenna used for TWR [19], the gain of the single-slot structure is enhanced but the XPD and port isolation are low. For the miniaturized, single-slot, tapered slot antenna proposed in [20], the peak gain, XPD, and port isolation are lower than the proposed antenna.

Table 2. The performance comparisons of the dual-polarized TSAs.

\begin{tabular}{|c|c|c|c|c|c|}
\hline Ref. & $\begin{array}{c}\text { Relative } \\
\text { Bandwidth } \\
(\%)\end{array}$ & $\begin{array}{c}\text { Element } \\
\text { Dimensions } \\
\left(\lambda_{L}\right)\end{array}$ & $\begin{array}{l}\text { Peak } \\
\text { Gain } \\
\text { (dBi) }\end{array}$ & $\begin{array}{l}\text { XPD } \\
(\mathrm{dB})\end{array}$ & $\begin{array}{l}\text { Port } \\
\text { Isolation } \\
\text { (dB) }\end{array}$ \\
\hline [14] & 158.2 & $0.55 \times 0.50$ & 10.5 & $\geq 20$ & $\geq 30$ \\
\hline [15] & 129 & $0.82 \times 0.81$ & 9.4 & $\geq 18$ & $\geq 22.3$ \\
\hline [16] & 55 & $0.81 \times 0.67$ & 3 & / & $\geq 15$ \\
\hline [17] & 120 & $1.62 \times 0.87$ & 12 & $\geq 20$ & $\geq 29.5$ \\
\hline [18] & 100.1 & $1.80 \times 0.54$ & 10 & $\geq 18$ & $\geq 23$ \\
\hline [19] & 160.9 & $0.65 \times 0.48$ & 15.8 & $\geq 16.2$ & $\geq 17$ \\
\hline [20] & 173 & $0.35 \times 0.35$ & 8.6 & $\geq 17.2$ & $\geq 28$ \\
\hline This work & 147.8 & $0.44 \times 0.44$ & 11 & $\geq 20$ & $\geq 32$ \\
\hline
\end{tabular}

With a relatively low profile, the proposed antenna achieves high-efficiency radiation at low frequencies and high gain characteristics at high frequencies. Due to the miniaturized profile, the peak gain of the proposed tapered slot structure can be further improved by adding a lens. Thus, it has obvious advantages in the application of penetrating detection systems or communication systems. The dual-polarized configuration can be used for analyzing the polarization features of the target echo or polarization diversity.

\section{Conclusions}

This paper proposes a novel dual-loop double-slot structure used for the dual-polarized antipodal tapered slot antenna that operates between 0.6 and $4 \mathrm{GHz}$. The antenna implements a hybrid magnetoelectric structure and new Fibonacci slot edges to overcome the shortcomings of ATSA and DSATSA in terms of asymmetric radiation patterns, low gains, and large profiles. Through numerical simulations of evolutionarily progressive structural modifications, the radiation mechanisms are revealed. A low-loss balun-divider structure is also proposed to feed the combined dual-polarized antenna. The experimental measurements demonstrate the superiority of the proposed DP-DSATSA and validate its design. Since this paper focuses on the improvement of the basic radiating structure, the performance can be further enhanced by inserting a parasitic structure, such as a metalens. Dual-polarized antennas can obtain more information of the target. It is feasible to make image fusion and polarization classification of the human body through polarization information. Thus, the antenna has good application prospects in the field of penetrating detection and human posture recognition.

Author Contributions: Conceptualization, G.Y. and S.Y.; methodology, G.Y. and F.Z.; software, G.Y.; validation, G.Y., S.Y. and F.Z.; formal analysis, G.Y.; investigation, G.Y. and Y.J.; resources, Y.J.; data curation, G.Y.; writing—original draft preparation, G.Y.; writing—review and editing, S.Y. and X.Z.; 
visualization, G.Y.; supervision, G.F.; project administration, X.Z.; funding acquisition, G.F. All authors have read and agreed to the published version of the manuscript.

Funding: This research was funded by the National Key Research and Development Plan, grant number 2018YFC0810200, ZH, grant number 30201, and National Natural Science Foundation, grant number 61827803

Conflicts of Interest: The authors declare no conflict of interest.

\section{References}

1. Wang, X.-Y.; Tang, S.-C.; Yang, L.-L.; Chen, J.-X. Differential-Fed Dual-Polarized Dielectric Patch Antenna with Gain Enhancement Based on Higher Order Modes. IEEE Antennas Wirel. Propag. Lett. 2020, 19, 502-506. [CrossRef]

2. Park, J.; Johnson, J.T.; Majurec, N.; Frankford, M.; Stewart, K.; Smith, G.E.; Westbrook, L. Simulation and analysis of polarimetric radar signatures of human gaits. IEEE Trans. Aerosp. Electron. Syst. 2014, 50, 2164-2175. [CrossRef]

3. Li, M.; Li, Q.L.; Wang, B.; Zhou, C.F.; Cheung, S.W. A Low-Profile Dual-Polarized Dipole Antenna Using Wideband AMC Reflector. IEEE Trans. Antennas Propag. 2018, 66, 2610-2615. [CrossRef]

4. Mirmozafari, M.; Zhang, G.; Fulton, C.J.; Doviak, R.J. Dual-Polarization Antennas with High Isolation and Polarization Purity: A Review and Comparison of Cross-Coupling Mechanisms. IEEE Antennas Propag. Mag. 2018, 61, 50-63. [CrossRef]

5. Liu, Y.; Zhou, W.; Yang, S.; Li, W.; Li, P.; Yang, S. A Novel Miniaturized Vivaldi Antenna Using Tapered Slot Edge with Resonant Cavity Structure for Ultrawideband Applications. IEEE Antennas Wirel. Propag. Lett. 2016, 15, 1881-1884. [CrossRef]

6. Wang, N.-N.; Fang, M.; Chou, H.-T.; Qi, J.-R.; Xiao, L.-Y. Balanced Antipodal Vivaldi Antenna with Asymmetric Substrate Cutout and Dual-Scale Slotted Edges for Ultrawideband Operation at Millimeter-Wave Frequencies. IEEE Trans. Antennas Propag. 2018, 66, 3724-3729. [CrossRef]

7. Li, X.; Zhou, H.; Gao, Z.; Wang, H.; Lv, G. Metamaterial Slabs Covered UWB Antipodal Vivaldi Antenna. IEEE Antennas Wirel. Propag. Lett. 2017, 16, 2943-2946. [CrossRef]

8. Wang, Y.; Wang, G.; Gao, X.; Zhou, C. Double-slot Vivaldi antenna with improved gain. Electron. Lett. 2013, 49, 1119-1121. [CrossRef]

9. So, Y.; Kim, W.; Kim, J.; Yong, Y.J.; Park, J. Double-slot antipodal Vivaldi antenna for improved directivity and radiation patterns. In Proceedings of the 2016 International Symposium on Antennas and Propagation (ISAP), Okinawa, Japan, 24-28 October 2016; pp. 382-383.

10. Wang, Y.-W.; Yu, Z.-W. A Novel Symmetric Double-Slot Structure for Antipodal Vivaldi Antenna to Lower Cross-Polarization Level. IEEE Trans. Antennas Propag. 2017, 65, 5599-5604. [CrossRef]

11. Malakooti, S.-A.; Moosazadeh, M.; Ranasinghe, D.C.; Fumeaux, C. Antipodal Vivaldi Antenna for Sum and Difference Radiation Patterns With Reduced Grating Lobes. IEEE Antennas Wirel. Propag. Lett. 2017, 16, 3139-3142. [CrossRef]

12. Zhang, Y.; Li, E.; Wang, C.; Guo, G. Radiation Enhanced Vivaldi Antenna With Double-Antipodal Structure. IEEE Antennas Wirel. Propag. Lett. 2016, 16, 561-564. [CrossRef]

13. Zhu, S.; Liu, H.; Wen, P.; Du, L.; Zhou, J. A Miniaturized and High Gain Double-Slot Vivaldi Antenna Using Wideband Index-Near-Zero Metasurface. IEEE Access 2018, 6, 72015-72024. [CrossRef]

14. Sonkki, M.; Sanchez-Escuderos, D.; Hovinen, V.; Salonen, E.T.; Ferrando-Bataller, M. Wideband Dual-Polarized Cross-Shaped Vivaldi Antenna. IEEE Trans. Antennas Propag. 2015, 63, 2813-2819. [CrossRef]

15. Dzagbletey, P.A.; Shim, J.Y.; Jeong, J.Y.; Chung, J.-Y. Dual-polarized Vivaldi antenna with quarter-wave balun feeding. In Proceedings of the 2017 Asia-Pacific International Symposium on Electromagnetic Compatibility (APEMC), Seoul, Korea, 20-23 June 2017; pp. 108-110.

16. Song, L.; Zhou, H. Wideband dual-polarized Vivaldi antenna with improved balun feed. Int. J. Microw. Wirel. Technol. 2018, 11, 41-52. [CrossRef]

17. Chen, D.; Wang, K.; Zhu, W.; Wang, L.; Liu, Z.; Wang, T.; Gao, J.; Zhu, S. 2-40 GHz dual-band dual-polarised nested Vivaldi antenna. IET Microw. Antennas Propag. 2019, 13, 163-170. [CrossRef]

18. Kim, W.; Park, J.; Park, H.; Yoon, Y.J. Radiation characteristics enhancement of dual-polarized antipodal Vivaldi antenna using double-slot structure. Microw. Opt. Technol. Lett. 2019, 62, 1245-1251. [CrossRef]

19. Cicchetti, R.; Cicchetti, V.; Faraone, A.; Foged, L.; Testa, O. A Compact High-Gain Wideband Lens Vivaldi Antenna for Wireless Communications and Through-the-Wall Imaging. IEEE Trans. Antennas Propag. 2020, 69, 1. [CrossRef]

20. Dzagbletey, P.A.; Shim, J.-Y.; Chung, J.-Y. Quarter-Wave Balun Fed Vivaldi Antenna Pair for V2X Communication Measurement. IEEE Trans. Antennas Propag. 2019, 67, 1957-1962. [CrossRef] 